Article

\title{
Assessing Landsat Fractional Ground-Cover Time Series across Australia's Arid Rangelands: Separating Grazing Impacts from Climate Variability
}

\author{
Jason Barnetson ${ }^{1,+, \neq *}$, Stuart Phinn ${ }^{2, \ddagger}$, Peter Scarth ${ }^{3, \ddagger}$ and Robert Denham ${ }^{4, \ddagger}$ \\ 1 University of Queensland, School of Earth and Environment Sciences, Remote Sensing Research Centre; \\ jasonbarnetson@gmail.com \\ 2 University of Queensland, School of Earth and Environment Sciences, Remote Sensing Research Centre, \\ Joint Remote Sensing Research Program; s.phinn@uq.edu.au \\ 3 Terrestrial Ecosystem Research Network; peter.scarth@gmail.com \\ 4 Queensland Department of Science, Information Technology and Innovation; \\ robert.denham@dsiti.qld.gov.au \\ * Correspondence: jasonbarnetson@gmail.com; Tel.: +61-8-8951-9259 \\ + Current address: Arid Zone Research Institute, Alice Springs, Northern Territory, Australia, 0870 \\ $\ddagger$ These authors contributed equally to this work.
}

\begin{abstract}
Suitable measures of grazing impacts on ground cover, that enable separation of the effects of climatic variations, are needed to inform land managers and policy makers across the arid rangelands of the Northern Territory of Australia. This work developed and tested a time-series, change-point detection method for application to time series of vegetation fractional cover derived from Landsat data to identify irregular and episodic ground-cover growth cycles. These cycles were classified to distinguish grazing impacts from that of climate variability. A measure of grazing impact was developed using a multivariate technique to quantify the rate and degree of ground cover change. The method was successful in detecting both long term ( $>3$ years) and short term $(<3$ years) growth cycles. Growth cycle detection was assessed against rainfall surplus measures indicating a relationship with high rainfall periods. Ground cover change associated with grazing impacts was also assessed against field measurements of ground cover indicating a relationship between both field and remotely sensed ground cover. Cause and effects between grazing practices and ground cover resilience can now be explored in isolation to climatic drivers. This is important to the long term balance between ground cover utilisation and overall landscape function and resilience.
\end{abstract}

Keywords: fractional ground cover; non-photosynthetic vegetation; landsat; standardised precipitation index; episodic rainfall; landsat; time series; growth-cycles 


\section{Introduction}

\subsection{Understanding change in Australia's arid rangelands}

An understanding of change in Australia's rangelands has evolved from early concepts of equilibrium continuum in landscape system modelling. A system functioning in an equilibrium continuum is described by [1] as its trend along a path of deterministic succession. This path of deterministic succession is argued by others to rarely exist in arid rangelands [2]. Unlike a path of succession, landscape processes in the arid rangelands have been described as a discrete set of "states" that change or transition from one to another. State and transition changes, described as non-continuous and irreversible, have been observed as a result of management practice. These non-continuous changes are not easily explained by succession or continuous based modelling [2]. State and transition modelling however explains change through the concept of resilience. Resilience as described by [3] is a measure of the persistence of a system and its ability to absorb change and disturbance. The degree and direction of the resilience of a system through time can be described as its trend. Trend in an arid rangeland system is influenced by both management practices and environmental fluctuations. Separating one from the other is a significant challenge. These foundation concepts of state and transition, resilience through persistence, trends in management and environmental fluctuations are well researched and embedded in the literature $[2,4,5]$. The challenges they present and the potential uses of remote sensing is discussed further.

\subsection{Monitoring change; its complexities, recent advancements and opportunities}

Monitoring Australia's rangelands involves understanding the dynamics of management-induced changes over time and identifying causal relationships that guide improved management practices [2]. Many problems and challenges exist in doing so. Complexities of determining change and its trend is inherently fraught with difficulty [6]. Existing research suggests that remote sensing is a possible solution $[2,7,8]$. It recommends that ongoing development should focus on robust and efficient methods [6] that utilise accessible and scale appropriate imagery [9], accurately reflect or depict the processes of interest $[9,10]$ and importantly characterise irregular or episodic climatic drivers from known and un-known anthropogenic land management practices [2]. Advances in remotely sensed data availability and methods are challenging these historical problems $[9,11]$. Key breakthroughs include: the unlocking of the USGS Landsat imagery holdings, dense time series are now no longer the domain of coarse and broad scale sensors [11]; development and proliferation of high performance computing facilities and algorithm development [12], reducing exhaustive and intensive processing and; better methods to predict ground cover components, through spectral un-mixing techniques [13-16]. The opportunity to explore the dynamics of ground cover change as it relates directly to management practices is a practical possibility. Improvements in management practices can be made with an improved understanding of landscape change and its resilience to change [3].

\subsection{A time series approach}

Existing time series vegetation change detection methods have been developed in more regular seasonally driven climates including $[17,18]$ and $[19]$. The TIMESAT method of $[18,19]$ was developed to characterise seasonal response of vegetation growth in multi-temporal imagery including AVHRR and MODIS. A smoothed time series is used to extract seasonal growth parameters that are then used to determine vegetation growth metrics. TIMESAT is a useful method for characterising the overall pattern or shape of a regular seasonally driven time series. Arid vegetation climate responses are more irregular and difficult to characterise. The BFAST or Breaks For Additive Seasonal and Trend method de-constructs a time series into seasonal phenological, overall trend and remainder components [17]. Unlike the TIMESAT method that is focused on the growing component of the time 
series the BFAST method exploits the full temporal detail of the time series. Growth patterns and seasonal shapes in the temporal detail are assessed to detect both abrupt or stepped changes and gradual or gentle linear trends. A decomposition model is used to fit a piece-wise linear trend and seasonal model. An iterative process is next undertaken to detect change or breakpoints in the time series. Breakpoints are easiest to detect where noise levels are low and seasonal amplitude high. [17] reported that measurable seasonal amplitude was not apparent in NDVI imagery in arid and frozen areas. This type of seasonal phenological modelling in arid environments is problematic. A gap exists in availability of suitable measures and methods for arid and irregular climate driven environments. Development of specific methods and appropriate remotely sensed data is needed. Further to this, the inability to separate climatic drivers from land management practices is due in part to the limitations in available imagery and the dominance of inappropriate indices and time-series approaches [2]. Many studies have been limited to annual / biannual imagery or course resolution imagery at more regular temporal intervals.

\subsection{Research objectives}

The main objective of this research is to develop new and expand existing methods to differentiate and measure grazing impacts on ground cover from that of climatic variability in remotely sensed Landsat Fractional Ground Cover (LFGC) time series data. Utilising advancements in spectral un-mixing methods used in the development of the LFGC data by [15] and [16], improved estimates of actual ground cover information vs. indices of ground cover, at an appropriate temporal and spatial scale, is now accessible and able to be efficiently processed in a dense time series manner, to further understand differences in ground cover change induced by management and climate. To do so this research first developed and tested an automated method to identify irregular growth cycles in LFGC time series data with the aim to identify and attribute the most distinguishable periods of livestock pasture utilisation. The rate and degree of ground cover decline within each utilisation period providing a measure of climate adjusted management impact.

Irregular or episodic ground cover growth cycle detection involved the development of an adapted time-series change-point detection method. LFGC remotely sensed imagery developed by [15] and [16] models the fractional proportions of ground cover as: green or photosynthetic vegetative (PV) cover; dead or non-photosynthetic vegetative (NPV) cover; and bare earth non vegetative cover; from field measured observations. Illustrated in figure 1 each fraction differs from one another throughout their growth cycles. Any attempt to decouple climate from management effects in LFGC should investigate such differences. The two major growth cycles of 2001 and 2010 illustrated are an example of these differences. Beginning with the growth of vegetation cover in response to rainfall, the NPV or dry / low photosynthetic fraction is observed to be significantly higher than that of the PV response. This is both a process of growth, senescence and accumulation of dry plant material and a dominance of the vegetation fraction. The later a result of plant adaptations of arid / semi-arid plant species that aim to lower photosynthesis and transpiration rates, to conserve water [20]. The first change point is identified as the upper growth point or peak of the NPV response. Illustrated in figure 1 this is the point whereby climate driven growth has ceased and decline is observed to follow. The trough is the other change point whereby either ground cover vegetation is observed to have been completely removed and / or climate begins to influence growth once again. The derivative of a statistical model was used to identify these change or break points in NPV ground cover growth. Time series segmentation was then used to classify NPV ground cover growth cycles between each peak and decline break point. These cycles were further classified to distinguish grazing impacts from that of climate variability. A measure of grazing impact was developed using a multivariate technique to quantify the rate and degree of ground cover change. The method was successful in detecting both long term ( $>3$ years) and short term $(<1$ year) growth cycles. Growth cycle detection was assessed against rainfall surplus measures indicating a relationship with high rainfall periods. 
113 of ground cover indicating a relationship between both field and remotely sensed ground cover.

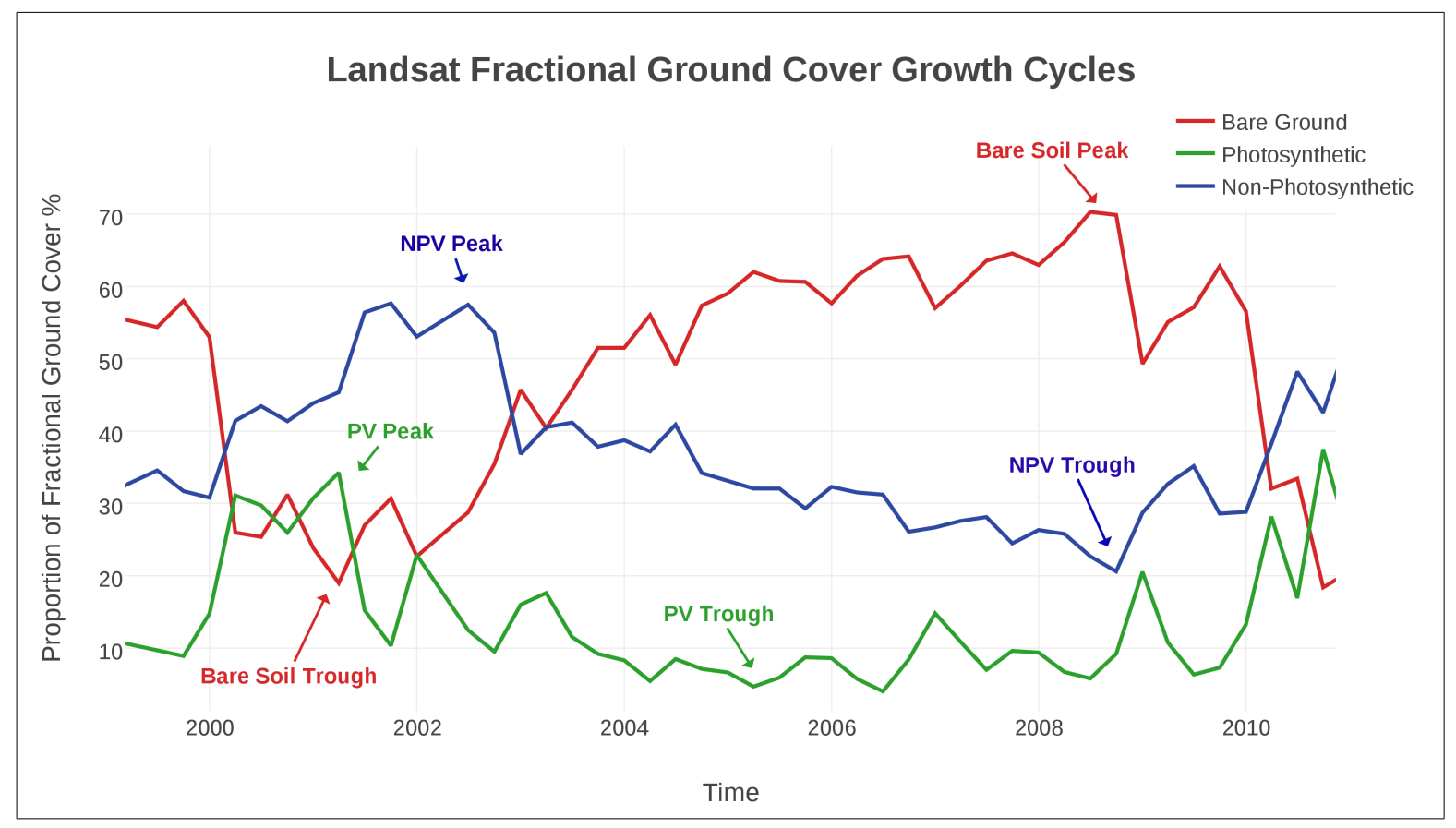

Figure 1. Landsat Fractional Ground Cover time-series plot of a one hectare area of arid rangeland. Major change points indicate ground cover growth cycles. The NPV growth cycle is notably larger than the PV.

114

\section{Materials and Methods}

\subsection{Study area}

The rangelands of the Northern Territory (NT) of Australia is an extensive $\left(\approx 1,000,000 \mathrm{~km}^{2}\right)$, largely intact natural landscape. Extensive areas of cleared land for agriculture, horticulture or urbanisation does not yet exist $(<10 \%)$. Mining, tourism and beef production are the main economic activities. The study area is focused on the central and southern pastoral rangelands of the NT, indicated in red in figure 2. This equates to almost a third of the NT and approximately 5\% of the Australian Rangelands. Rangeland grazing for beef production is the most extensive. Figure 3 illustrates two extensive land tenures: freehold Indigenous land used primarily for traditional living and some rangeland cattle grazing; and leasehold pastoral lands utilised primarily for rangeland cattle grazing. Native and introduced pastures in both tenures are managed in a rainfall driven natural system for animal production. Next figure 4 illustrates the three main climatic zones including: the tropical / monsoonal savannah forests and woodlands of the north; the sub-tropical to semi arid woodlands, shrub-lands and grasslands of the central zone; and the semi-arid to arid low open shrub-lands and grasslands of the south. The amount and regularity of rainfall changes from north to the south as does temperature and relative humidity. 


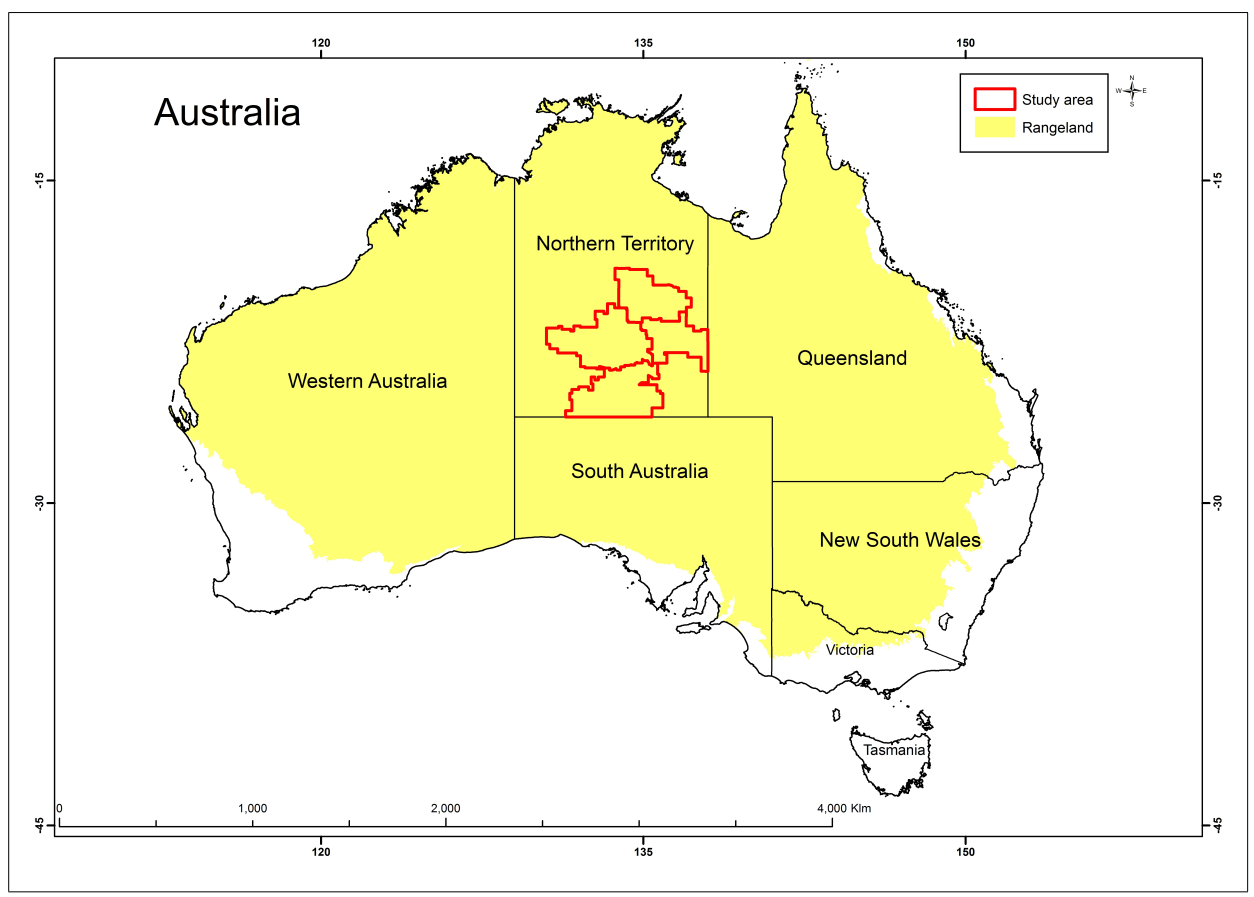

Figure 2. Map of the Australian Rangelands, highlighted in yellow, encompasses approximately 6 million sqkm or $81 \%$ of Australia. The study area focused on the central and southern regions of the NT, encompasses approximately $5 \%$ of the Australian Rangelands.

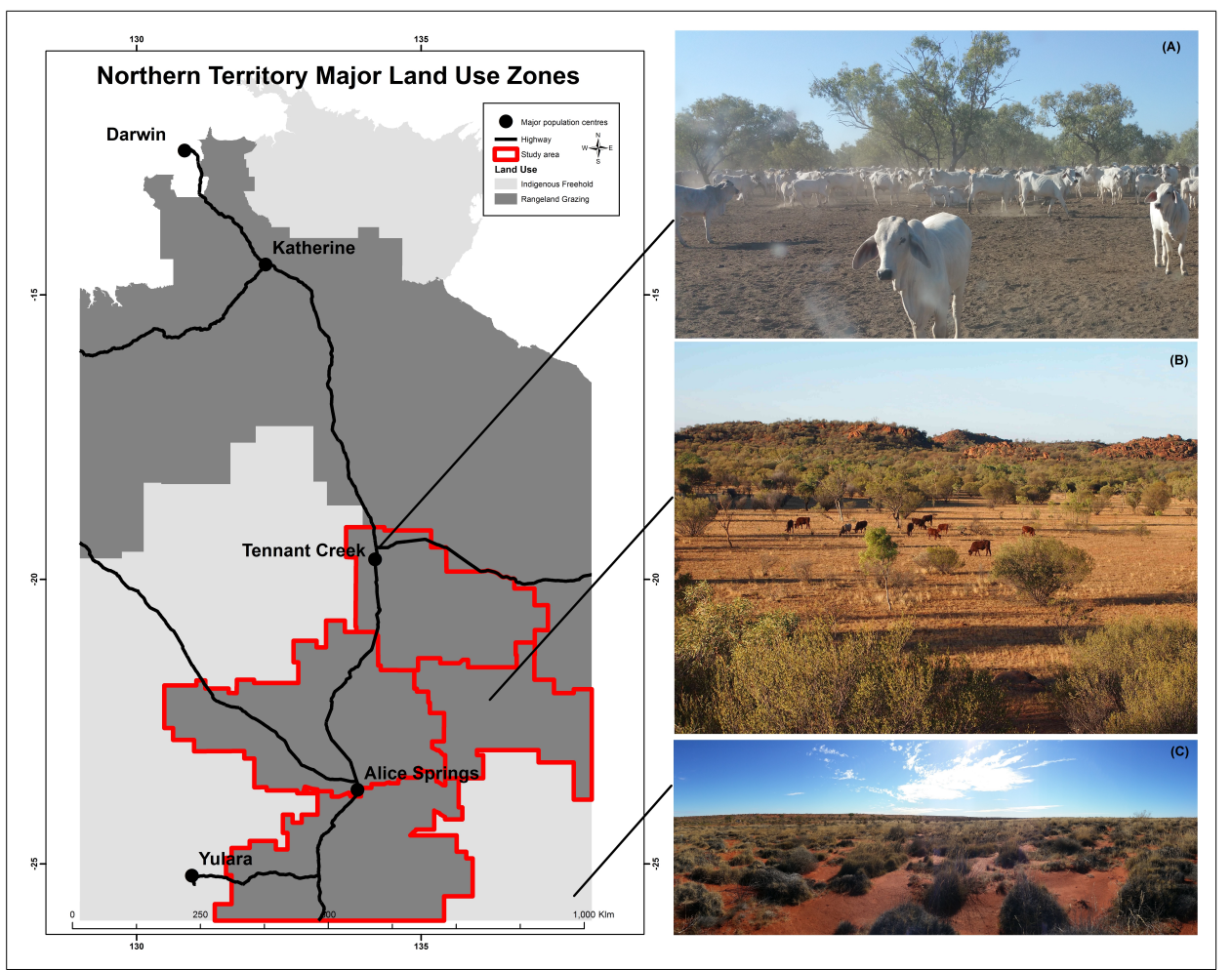

Figure 3. Extent of major land use zones including: A). Intensive rangeland cattle grazing in the northern parts of the study area; B).Less intensive grazing in the central parts of the study area (photo courtesy of Laurence Tait); and C). Indigenous freehold lands utilised for traditional land management practices and minimal $(<1 \%)$ rangeland cattle grazing. 


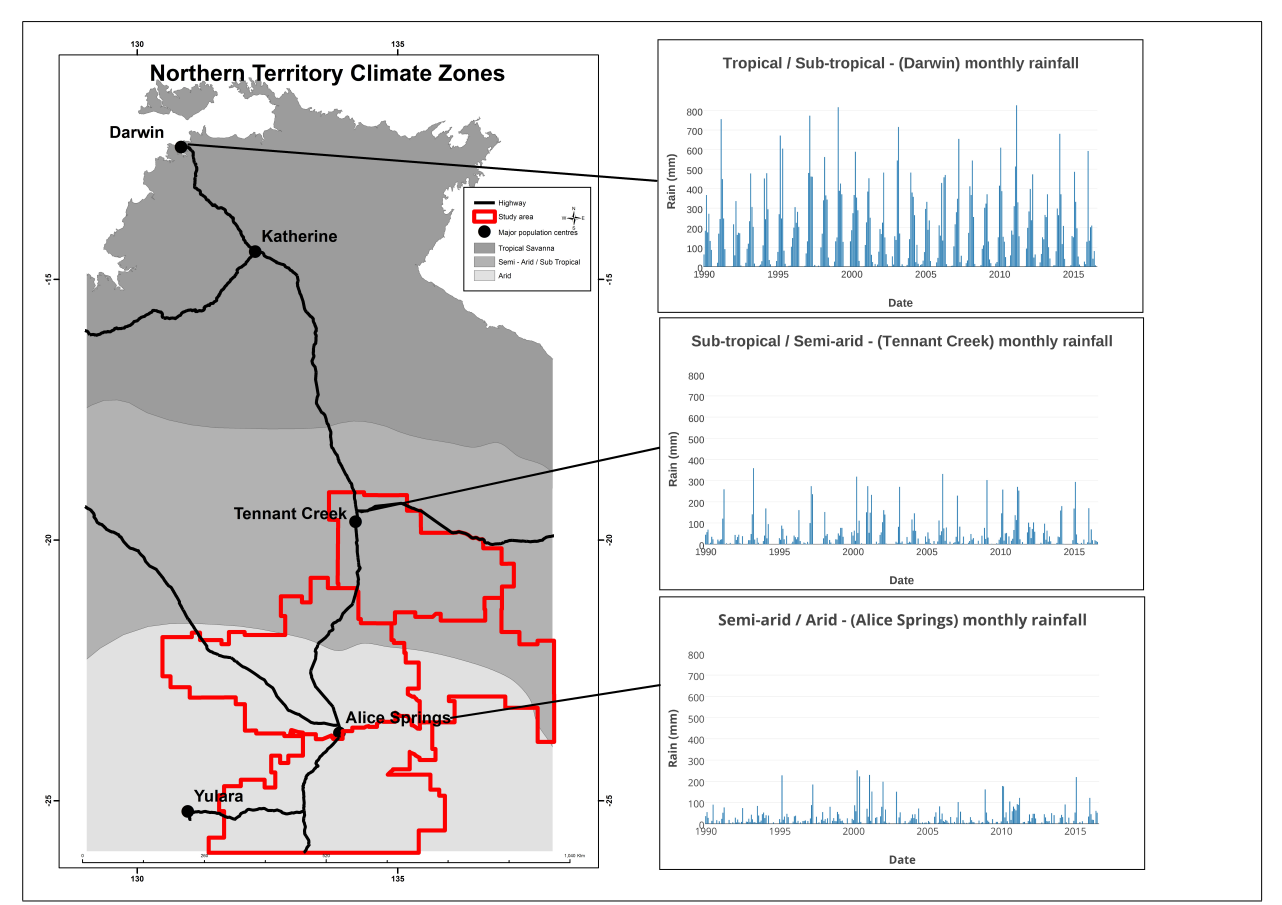

Figure 4. Three broad climate zones of the Northern Territory including the tropical / monsoonal savannah forest and woodlands of the northern zone, the sub-tropical to semi-arid woodlands, shrub-lands and grasslands of the central zone, and the semi-arid to arid shrub-lands and grasslands of the southern zone.

\subsection{Landsat Fractional Ground Cover Data (LFGC)}

\subsubsection{Suitability}

LFGC imagery is used in this study for a number of reasons. First Landsat being the longest archive of remotely sensed earth surface observations in the world [9] and spanning several decades it is most suited in detecting irregular and episodic vegetation change in an arid environment. Moderate spatial resolution multi-spectral image data will continue to be collected globally by several nations and is the most widely used source of environmental monitoring data. Next it provides the necessary spatial resolution to depict management related change. [21] and [22] suggest a spatial scale or grain of one hectare is important to most landscape scale processes and monitoring programs in rangelands. Lastly and importantly the LFGC method aims to model the fractions of ground cover of a remotely sensed image pixel from field based observations. These fractions include photosynthetic vegetative (PV) cover, dead or non-photosynthetic vegetative (NPV) cover, and bare earth non vegetative cover including rock and stone. Each fraction is represented by the three primary colours illustrated in the colour triangle in figure 5. An example LFGC image of the entire Northern Territory in figure 6 illustrates each fractions colour representation. Arid vegetation has adapted to reduce water loss through reducing respiration and photosynthesis [20]. [23] reported that traditional methods are limited in their ability to separate less photosynthetic vegetation from that of background soil. This low or non-photosynthetic cover (NPV) component of vegetation cover is dominant in arid landscapes as demonstrated in figure 6. LFGC unlike traditional remotely sensed vegetation methods aims to 'un-mix' or separate both the living and non-photosynthetic vegetation components from each other and from background earth, rock or stone. 


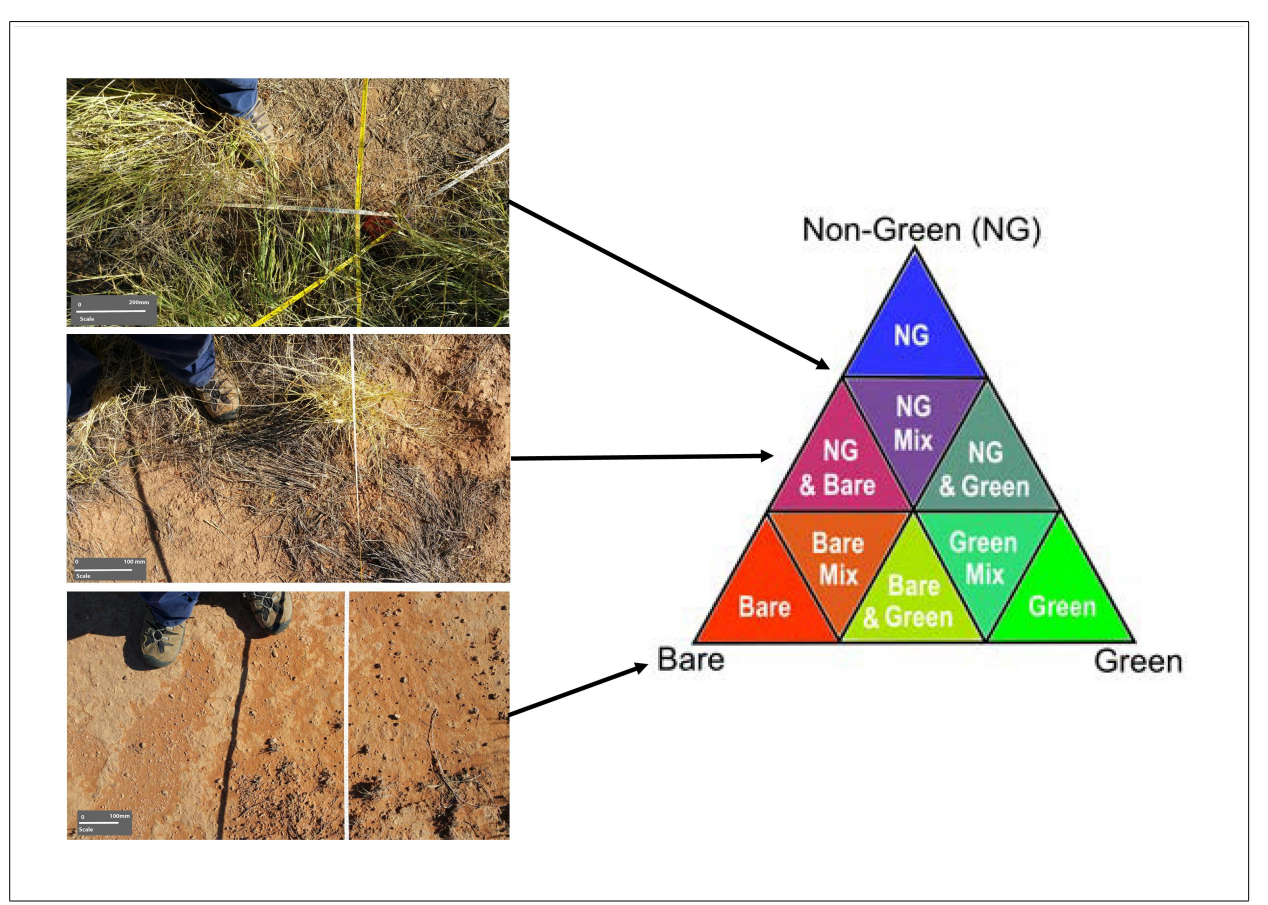

Figure 5. Field photographs of common fractional ground cover components and their corresponding colour triangle representation in the arid and semi-arid zones of the Northern Territory (Graphic courtesy of Rebecca Trevithick).

\subsubsection{Preprocessing and standardisation}

LFGC is derived from the US Geological Service (USGS) Landsat 5, 7 and 8 level one terrain corrected holdings. [24] and [25] have applied atmospheric, topographic and Bidirectional Reflectance Distribution Function (BRDF) radiometric calibrations to the Landsat data to derive surface reflectance imagery. Cloud masking has also been applied using techniques developed by [26]. Single date path-row images in 16 day intervals from 1987 to present will be used in a time series based analyses. The study area is resolved by 21 individual Landsat scenes (see Figure 7) that consists of $\approx 15$ thousand individual images. Manageable $2 \mathrm{~km}^{2}$ image squares or chips, centrally located over the field sites in figure 7, were subset from the larger image archive for time series method development and field site assessment.

\subsection{Field estimates of fractional ground cover}

The 568 field sites in figure 7 were established by the NT Department of Environment and Natural Resources Rangelands Monitoring Branch from 2013 to 2016 for the purposes of rangeland monitoring including the validation of LFGC imagery. Site stratification and location involved a desktop assessment of land and vegetation resource mapping and satellite imagery to ensure site homogeneity and representation. Patches of intact and minimally disturbed vegetation, no less than $100 \times 100 \mathrm{~m}$ in size were selected. Following the national standard ground cover field measurement method of [27], each site consists of 300 individual point intercept observer estimates. Utilising a laser pointer for the ground and mid vegetation layer $(<2 \mathrm{~m}$ above ground level) and a sight tube densitometer for upper canopy vegetation, fractional ground cover and projected foliage canopy cover intercepts are observed and recorded at one metre intervals along three star pattern arranged $100 \mathrm{~m}$ measuring tapes. 


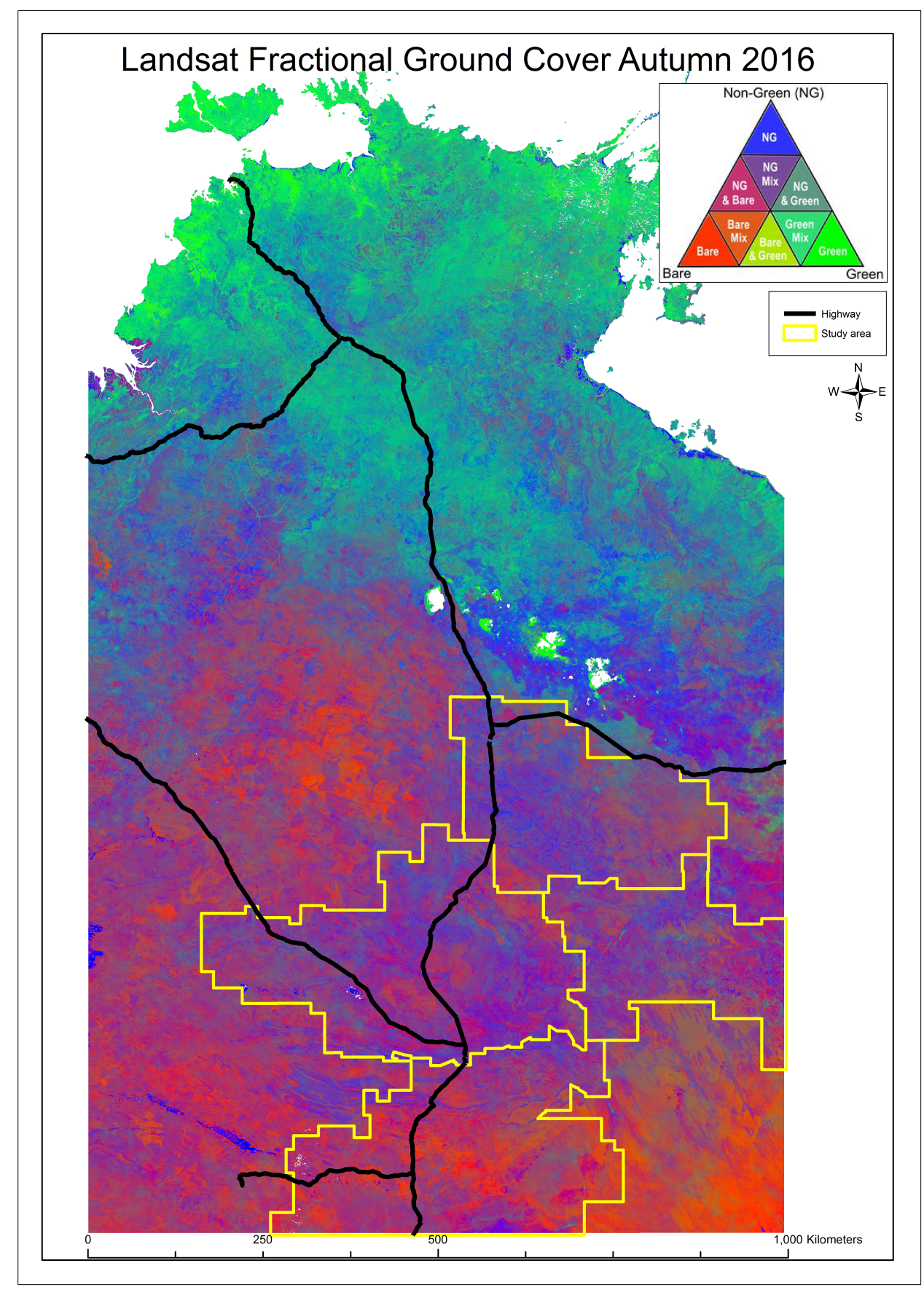

Figure 6. Example Landsat Fractional Ground Cover image of the Northern Territory illustrating each fractional components colour representation. Green or photosynthetic vegetation is seen across the northern tropical regions, blue non-photosynthetic vegetation can be seen through the central and southern zones and extensive red bare soil is evident across the southern sand plains and dune fields. 


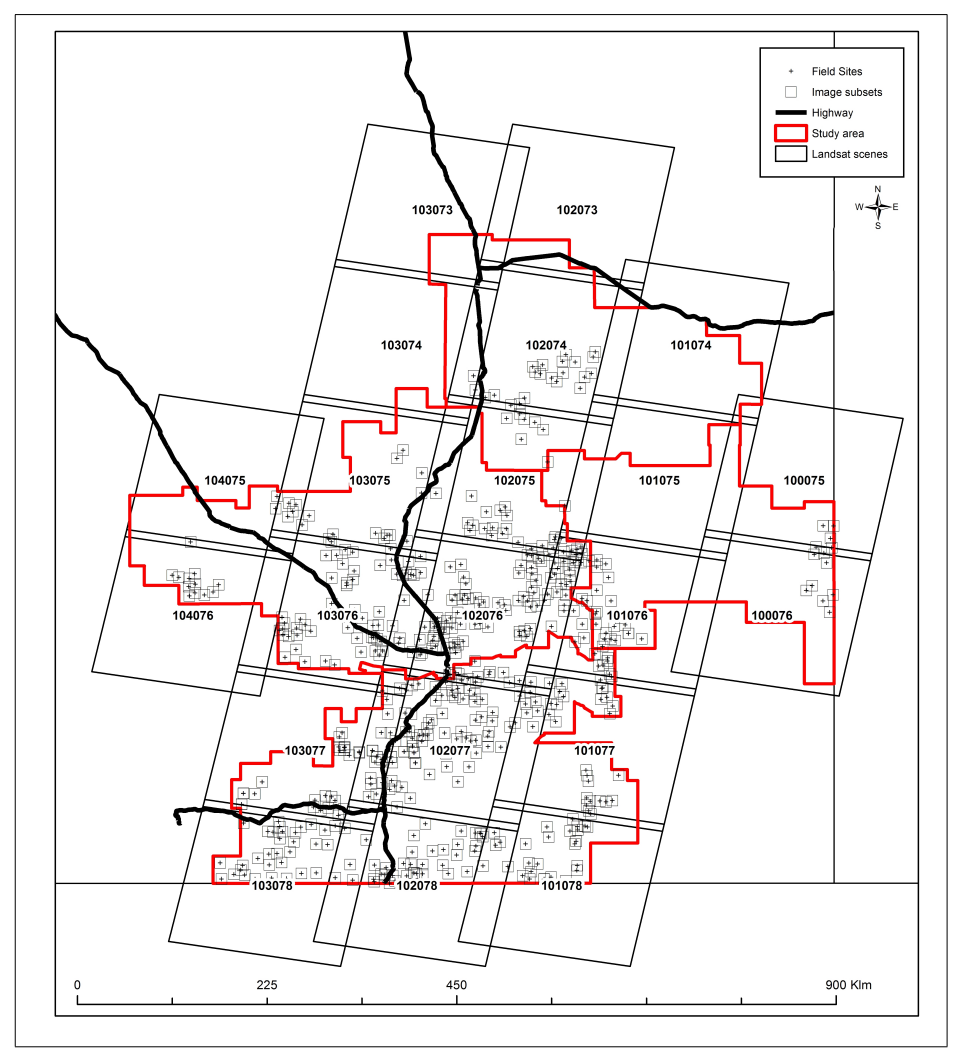

Figure 7. Location of both fractional ground cover field measurement sites and subset $2 \mathrm{~km}^{2}$ image chips centrally located over each field site.

\subsection{Gridded monthly rainfall surfaces}

A monthly rainfall surface, spanning the Landsat archives temporal range will be used in this study. Developed by [28] and accessed through an archive established by [29] this consists of an interpolated $5 \mathrm{~km}^{2}$ resolution raster grid. Created from a network of daily rainfall recording stations across the study area it provides a temporal and spatial representation of rainfall across the study area. Recording stations are, sparsely distributed and gaps in rainfall amounts exist. Trends and major anomalies are however detectable and useful to this study. 


\subsection{Time series analysis method}

Change point detection in both long and short term growth cycles is the aim of the first stage. A "change point" is defined as the point in a growth cycle were by a major phenological change has occurred. A growth cycle is defined as having two key components: (1) the response and accumulation of NPV ground cover to rainfall including its peak or maximum growth change point and, (2) its subsequent decline to a point of either complete ground cover removal or response to rainfall again, defined as its trough or minimum change point. Long term growth cycles are defined for the purposes of this study as those greater than three years in duration and the result of continued rainfall events. Short term cycles are less than three years but more typically one to two years and are likely attributed to annual - biannual rainfall cycles. Figure 8 illustrates an example of both long and short term growth cycles and their peak and trough points. Characterisation of each growth cycle is the next stage. Ground cover utilisation within each growth cycle is determined and classified, then the amount and rate of decline is assessed. The following describes each stage in detail.

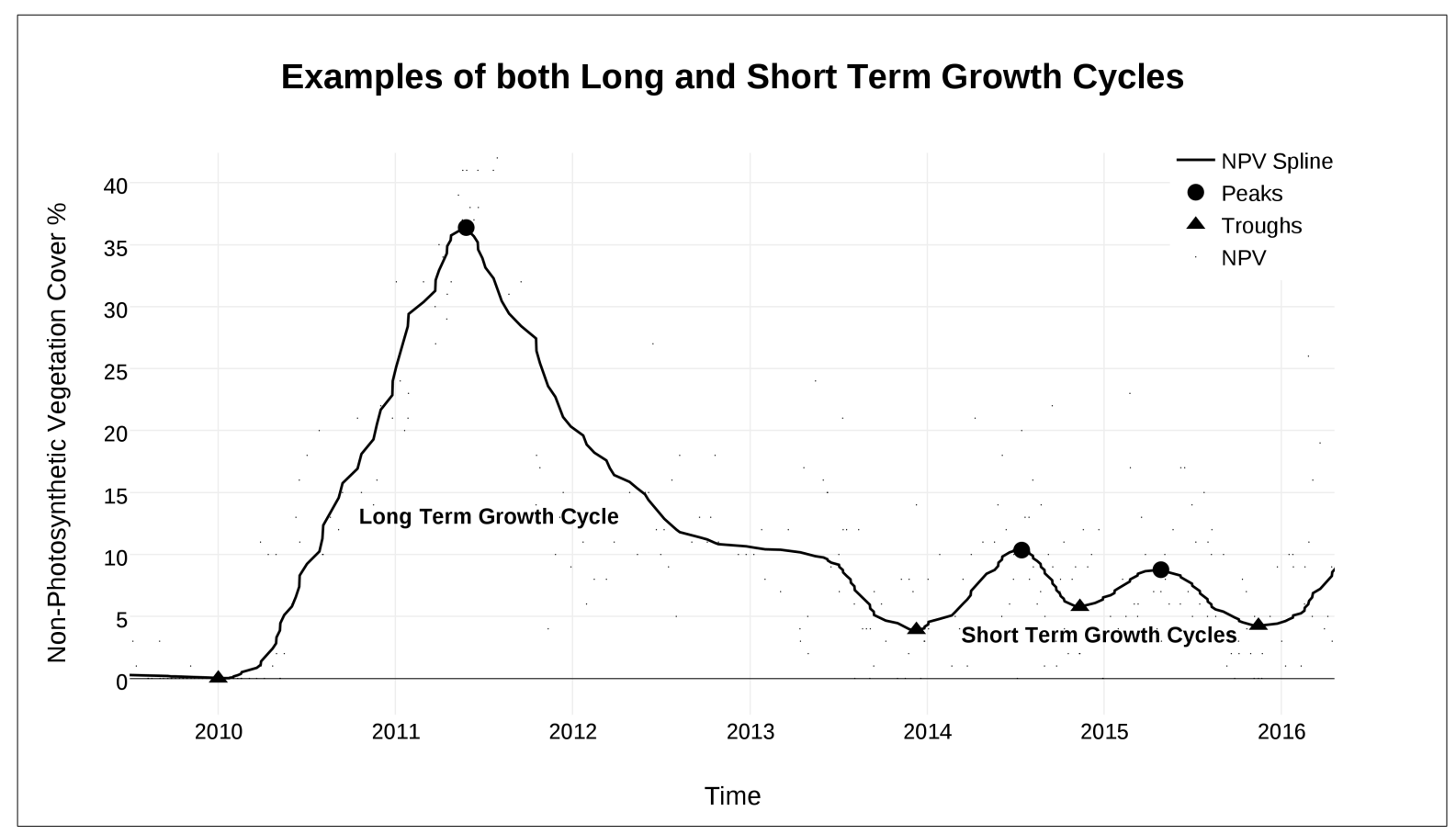

Figure 8. Example of long and short term growth cycles and their associated maximum growth peaks and minimum trough points. 


\subsubsection{Change point detection}

The first step in detecting change points in the NPV time series was to smooth the time series in an attempt to remove noise. Efforts have been taken to improve the signal to noise ratio through atmospheric, albedo and terrain corrections applied to the Landsat imagery in the pre-processing stages discussed in the LFGC data section. However soil moisture and its effects on soil brightness, reported by [23], and further atmospheric effects from smoke, dust, haze and light cirrus cloud are additional sources of noise in the LFGC imagery that are difficult to remove at the pre-processing stages. A method of interpolating a spline between individual NPV data points to smooth the time series and remove this noise, whilst still characterising the signal was used. The Python scientific programming module SCIPY was used to implement a one-dimensional smoothing spline fitted to each NPV time series. The smoothing spline is a method of fitting a curve to a set of noisy observations using a spline function. The next step was to locate the positions of the change points in the time-series. Defined as points of extremes i.e. maximum growth peaks and minimum troughs, we use a first derivative test to find these maxima and minima in the time-series. Differential statistics were used to calculate the first derivative of the spline function used to smooth the time-series. The point in the derivative time series that crosses the $x$ axis from positive to negative change is illustrated in plot (B) of figure 9 as the blue line. This is the point whereby growth has reached a local maximum peak and begins to decline as illustrated in the plot (A) of figure 9 as the coincidental blue line. The opposite negative to positive crossing point is the extreme minimum position in the derivative time series and is illustrated as the red vertical line in plots (A) \& (B) of figure 9.

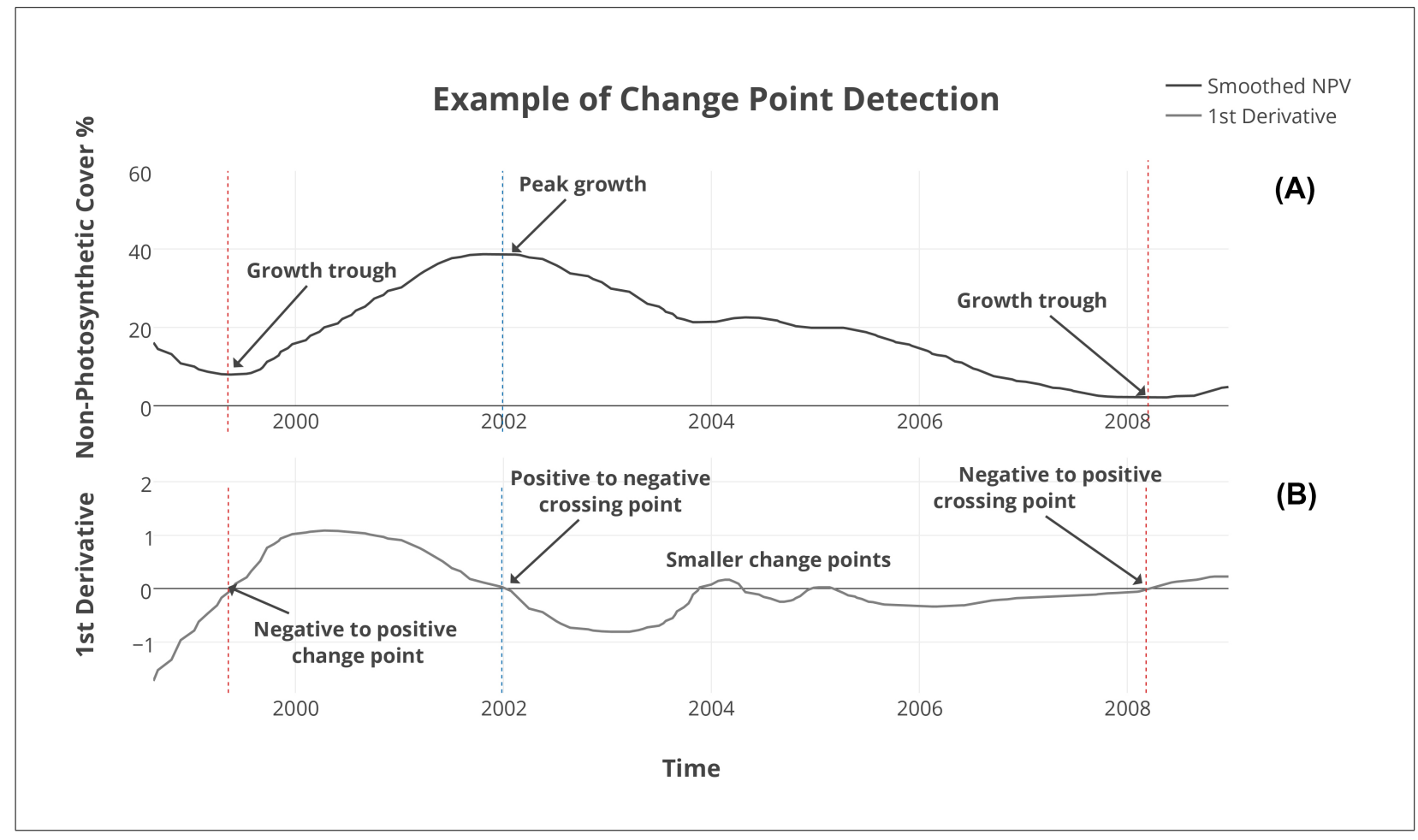

Figure 9. Example of minimum and maximum NPV change point detection. Plot (A) illustrates a time series of NPV cover, a smoothed spline fitted to the time series and the locations of the peak (blue) and (red) trough change points. Plot (B) is a first derivative time-series of the spline function in the top plot. The $x$ crossing axis points illustrated in blue and red are used to determine the locations of the maximum and minimum change points in the top plot. 


\subsubsection{Change point assessment}

Rainfall as the main driver of vegetation response and reported by [30] to be linearly correlated to ground cover growth in arid environments, was used to assess the accuracy of the detection of LFGC growth cycle peaks. The trough of the growth cycle is difficult to assess in this manner as it is a function of ground cover utilisation. Positive rainfall anomalies or peaks in the long term rainfall record were identified using the Standard Precipitation Index (SPI) of [31] and compared to that of the peaks detected in the NPV time series. SPI is a normalised index representing the probability of occurrence of an observed rainfall amount when compared with the rainfall climatology at a location over a long-term reference period. The $5 \mathrm{~km}^{2}$ gridded monthly rainfall surfaces were used to calculate SPI time series for the length of the Landsat archive. SPI enables rainfall conditions to be quantified over varying time scales. For example, shorter temporal windows can be used to determine temporary soil moisture changes in agricultural applications whereas longer windows can indicate water storage shortages and droughts. A long temporal analysis window of 36 months was chosen to detect anomalies present in infrequent / episodic rainfall patterns typical across the arid and semi-arid rangelands of the study area. Vegetation responds to rainfall at varying rates depending on factors aside from plant physiology, such as rainfall timing, soil temperature and soil type. A method of calculating the lag between rainfall and NPV growth was employed. A cross correlation technique was used to determine the relationship between NPV cover and SPI for each individual growth cycle in the time series. Cross correlation is the measure of similarity of two series as a function of the displacement of one relative to the other [32]. This displacement or offset value is calculated indicating the degree of positive or negative lag between the two variables throughout each individual growth cycle. Climate over the longer term contributes to each and every growth cycle, however the aim of this method is to identify the effects of rainfall acting upon each ground cover growth cycle as an assessment of the change point detection method. Figure 10 illustrates an example of an NPV and SPI time series for a particular growth cycle and their offset. The position of the NPV peak in the time series was next adjusted by this offset and the coincidental SPI value extracted at this location in the time series as the lag adjusted SPI for that NPV peak. Next, each lag adjusted SPI value was classified into the rankings in table 1 that come from the modified classification of [31] by [33]. Positive SPI values above 1 indicate moderate to extremely wet rainfall anomalies and vice versa for negative values less than negative 1 with normal to near normal in the 1 to -1 range. The percentage of positive rainfall SPI peaks from the time series of every field site across the study area provided an indication of the performance of the change detection method to detect NPV peak change points.

Table 1. Standardised Precipitation Index classification

\begin{tabular}{ccc}
\hline SPI Start & SPI End & Category \\
\hline 2 & $>2$ & Extremely Wet \\
1.5 & 1.99 & Very Wet \\
1.0 & 1.49 & Moderately Wet \\
-0.99 & 0.99 & Near Normal \\
-1.0 & -1.49 & Moderately Dry \\
-1.5 & -1.99 & Severely Dry \\
-2 & $<-2$ & Extremely Dry \\
\hline
\end{tabular}

\subsubsection{Growth cycle characterisation and utilisation segmentation}

Growth cycles were next identified from the peak and trough point locations detected in the time series. A growth cycle is described as the period in the time series from the minimum growth trough to the proceeding growth peak and followed by the proceeding trough. Each cycle based on its duration was then classified as either long $(>3 y r s)$ or short $(<3 y r s)$ term. The first stage of each growth cycle was defined as the period from the initial minimum growth trough to its 


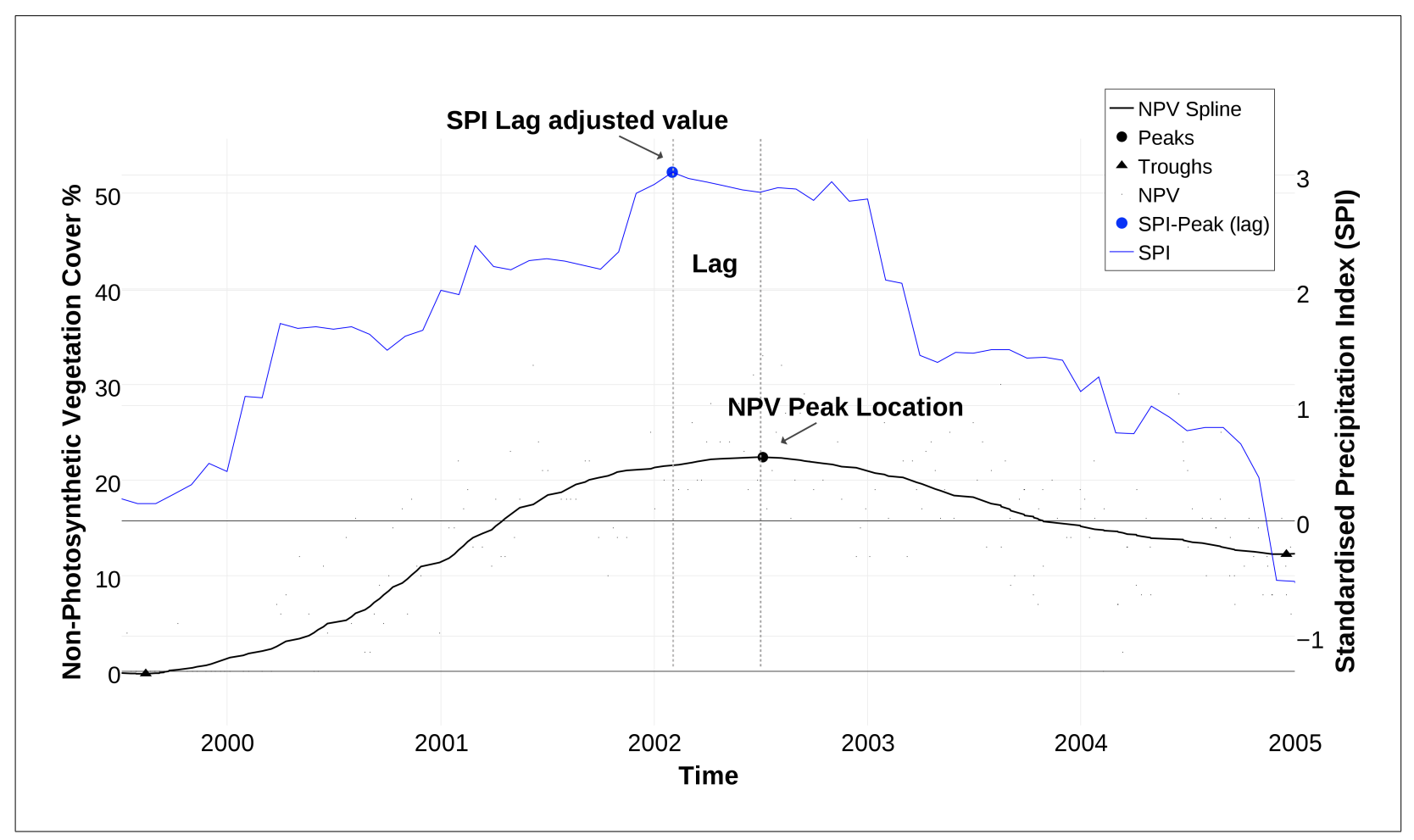

Figure 10. Example of NPV growth cycle and coincidental SPI time series. The NPV growth peak (black circle) and its lag or offset to the SPI time series (vertical dashed lines) is illustrated. The adjusted SPI value (blue circle) is also demonstrated.

peak. Ground cover including NPV cover increases in response to rainfall. Phenological processes of photosynthesis, growth, senescence and accumulation are occurring as are removal processes including grazing and decay. The next stage was defined as the period from the peak growth point to the next minimum trough point. Illustrated as the utilisation segment of a growth cycle in figure 11. Ground cover was observed to have reached a peak in both growth and accumulation. NPV cover begins to decrease. The effects from management practices such as grazing are considered to be most prominent during this stage and those of climate such as rainfall least prominent. Differences between individual time series with similar climate and vegetation characteristics were used to test this. Climate should mask any management related effects during periods of substantial growth. During periods of decline distinction between time-series as a result of differing management became evident.

\subsubsection{Rate and degree of NPV utilisation}

The decline in NPV ground cover during the utilisation stage of the growth cycle were measured in both their amount and their intensity. The rate of which it declines gave an insight into the intensity of the removal process. First a linear model was fitted to each utilisation segment from its peak growth point to its proceeding trough and the models slope used to determine the rate of which NPV ground cover declined for each utilisation segment. The amount of the decline provided a measure of the degree of both the spatial extent and amount of cover removed by grazing practices. Factors that complicate this included the distinction between palatable and unpalatable vegetation including woody vegetation and the distinction between detached plant material as litter and standing senescent plant material. Adapted from [18] and defined in figure 11 two measures were developed to begin to understand these differences. Both quantified the amount of cover decline as an approximation of the area under each utilisation segments curve. The larger area or integral 
encompassed the entire area under each utilisation curve, defined by the vertical axes of the peak and trough locations, the curve of the fitted spline and the horizontal base of zero cover. The smaller area / integral differed in that the horizontal base was defined by the trough point location. Differences between them provide insights into the challenges presented.

\subsubsection{LFGC assessment}

Confidence in measures of NPV ground cover decline begins with an assessment of the remotely sensed imagery product. An accuracy assessment of the LFGC NPV ground cover component was carried out to test the strength of the relationship between ground based measurements and remotely sensed ground cover. LFGC imagery acquired closest to the field measurement collection date with valid un-masked cloud free data was compared. Spatial averaging of a $3 \times 3$ pixel window over each site provided an image estimate of the NPV fraction for each approximately one hectare field site. Predicted and measured NPV measurements were compared and the degree of error reported.

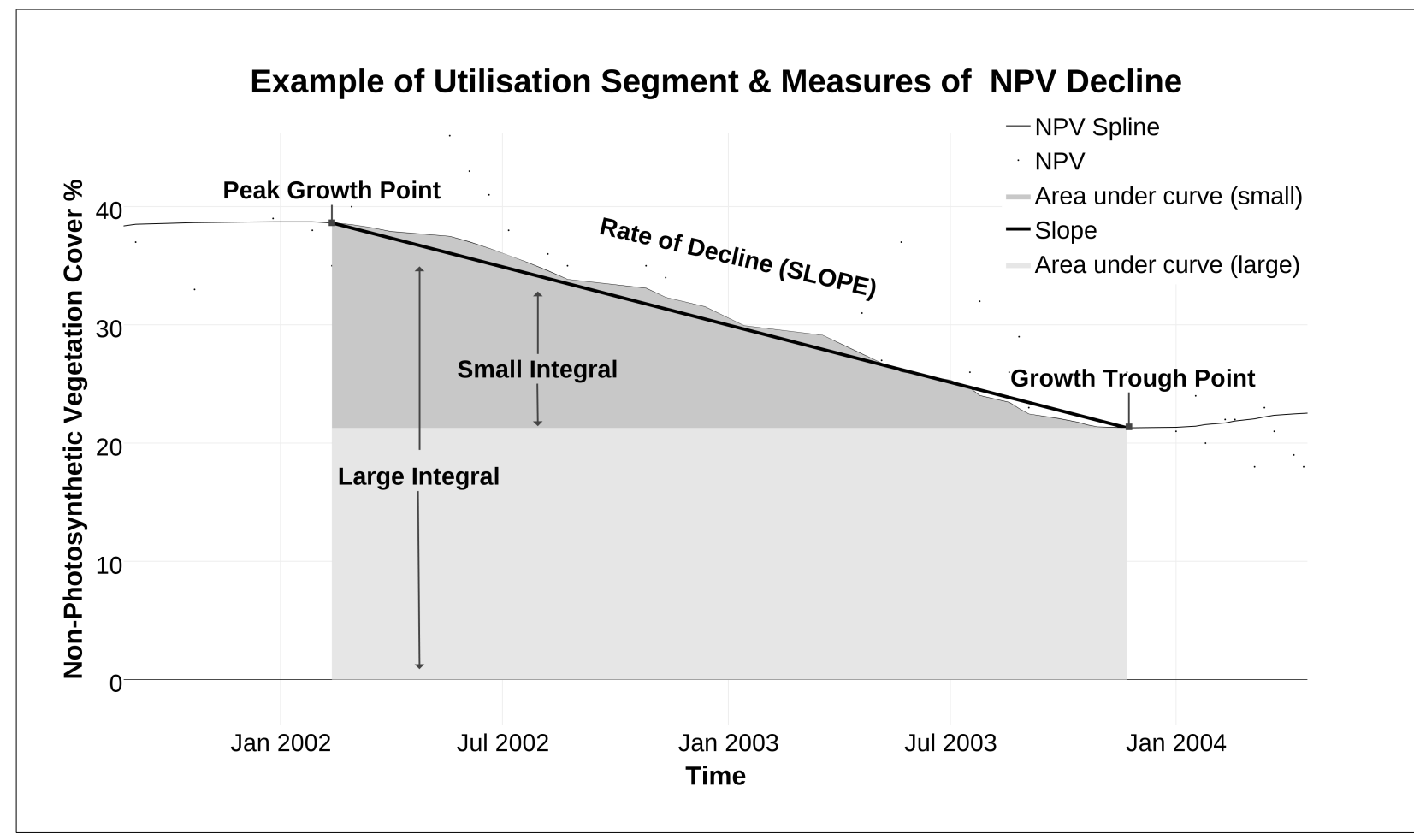

Figure 11. Example of a segmented long term growth cycle, the utilisation period is defined as the point from the growth peak to the proceeding trough, measures of both the rate and degree of utilisation are illustrated as a linear model of slope from the peak to the trough and the area under the curve. The large area under the curve integral has an $x$ axis base of zero and the smaller integral an adjusted base at the $y$ trough point. 
287

\section{Results}

\subsection{Time series analysis}

\subsubsection{Change point detection}

Figure 12 illustrates the proportion of NPV growth peaks that were associated with each Standardised Precipitation Index classification class. NPV growth peaks associated with long term growth cycles show the strongest relationship with all of the peaks detected in near normal to extremely wet conditions. The remainder shorter term peaks are associated with near normal conditions for the majority with a very small (5.6\%) detected in moderately dry conditions across the 568 field site time series.

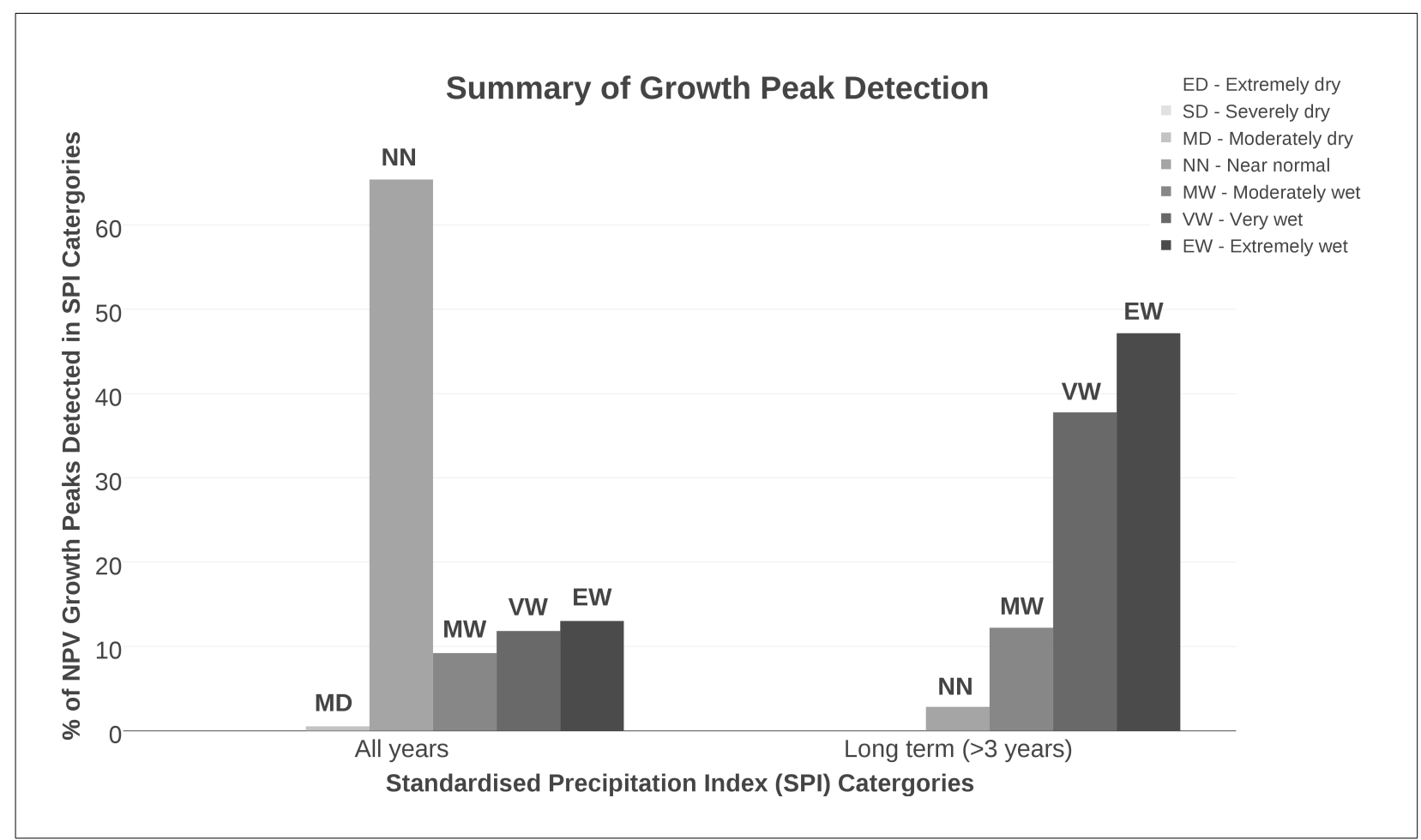

Figure 12. Results of NPV growth peak assessment. All Peaks were assessed in the series on the left of the chart and only the peaks associated with long term growth cycles were assessed in the series on the right. In both series less than $6 \%$ of the growth peaks were detected in periods of moderately negative SPI.

\subsubsection{Growth cycle characterisation}

Time series plots of four example grassland communities in figure 13, illustrate the methods ability to detect and characterise growth cycles between 2000 to 2016. Field site (A) is located in the sub-tropical to semi-arid tussock grasslands of the northern parts of the study area. Field site (B) is located in the semi-arid to arid chenopod grasslands of the southern parts of the study area. The time series of field site (C) is that of an introduced or improved pasture grassland. The final time series (D) is that of a field site in the extensive Spinifex (Triodia sp. hummock grasslands. 

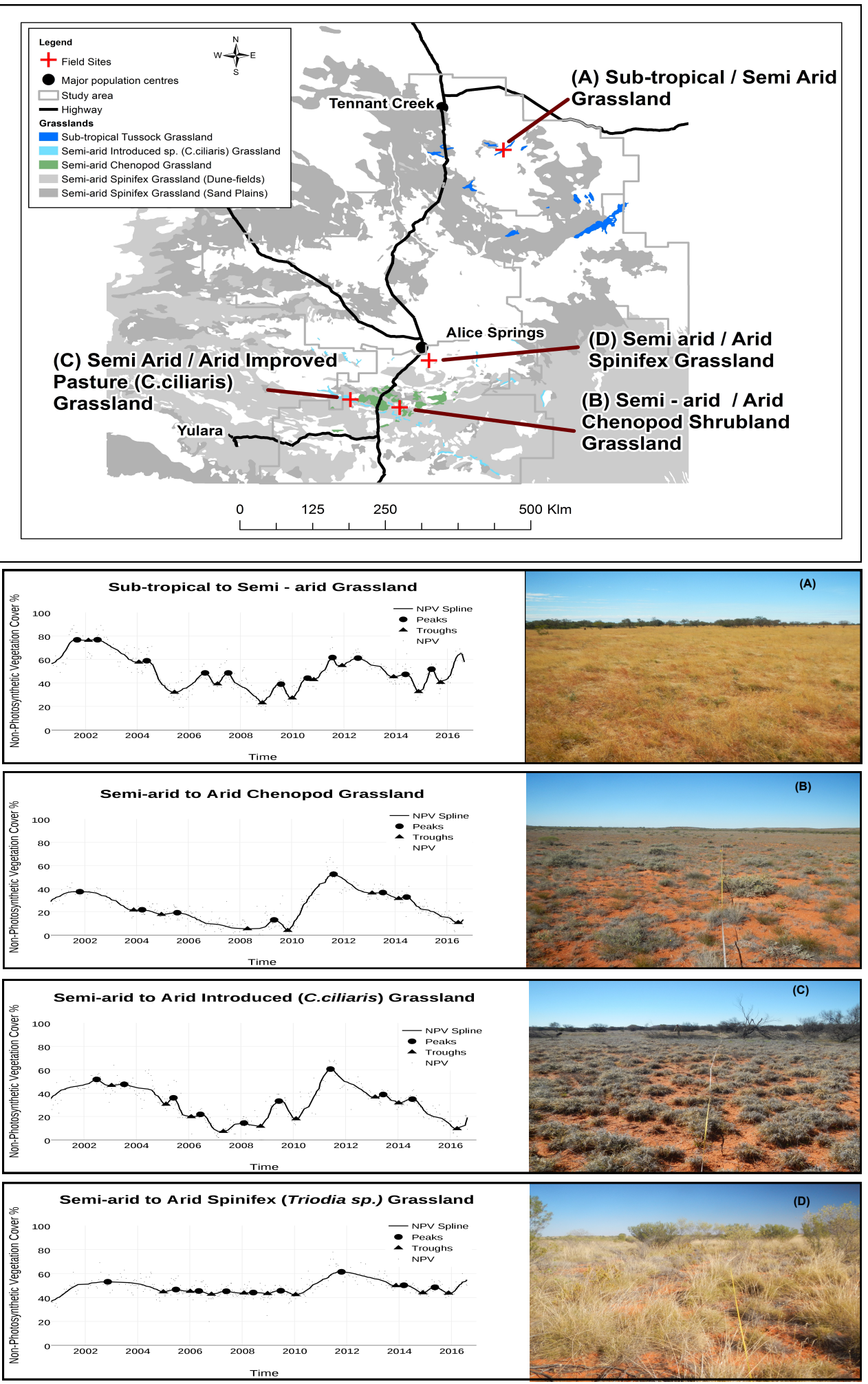

Figure 13. Field site time-series plots of four grassland communities across the study area.Each plot illustrates each sites growth cycles and associated growth peaks and troughs. 


\subsubsection{Growth cycle comparisons}

The growth cycles of a number of NPV time-series, randomly selected from across each of the image subset chips of the four previously selected field sites, is next presented. Figure 14 illustrates how the individual time series both converge or aggregate towards one another, and conversely separate from one another throughout their individual growth cycles.

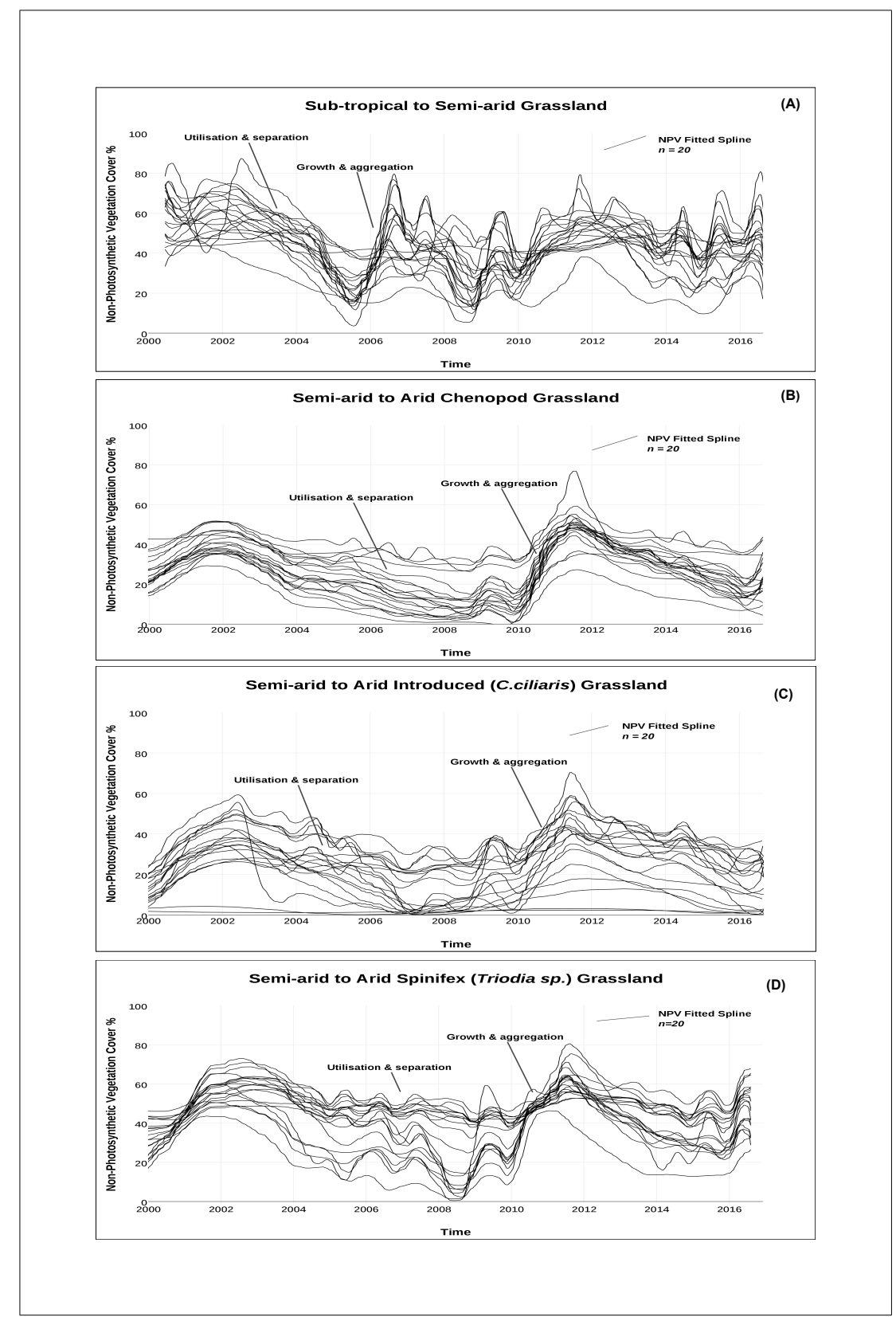

Figure 14. NPV time series plots of a number of randomly selected pixel locations across the image subsets of each of the same four selected field sites as figure 13. 


\subsubsection{Utilisation characterisation}

The utilisation segments of each of the four example field sites is next presented in figure 15. Each utilisation segment is distinguished in terms of its duration, shorter segments are labelled in red and longer in blue. Measures of NPV decline are defined as the small and large integral area under each utilisation segments curve. The smaller integrals encompassing the area from each cycles minimum decline point horizontally to its peak and the larger integrals from each plots zero base. The slope of each segment from its peak to its trough is shown as a dark line illustrating the rate of NPV decline.
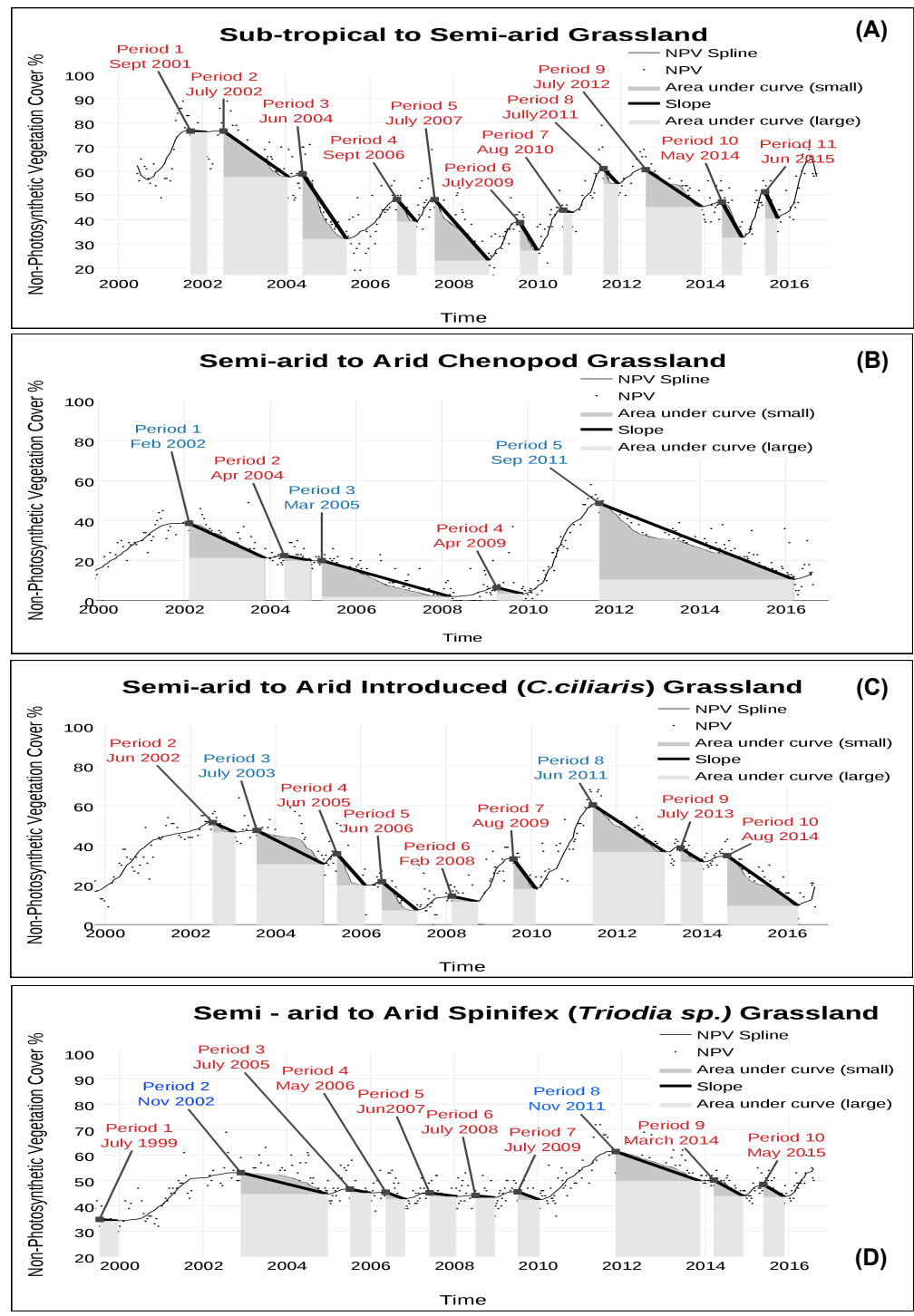

Figure 15. Example field site plots illustrating each sites growth cycle utilisation segments. Measures of utilisation are further illustrated as both the area under segments curve and the slope of each segment declines. 

The residual error and bias are also indicated.

\subsubsection{Field site comparisons}

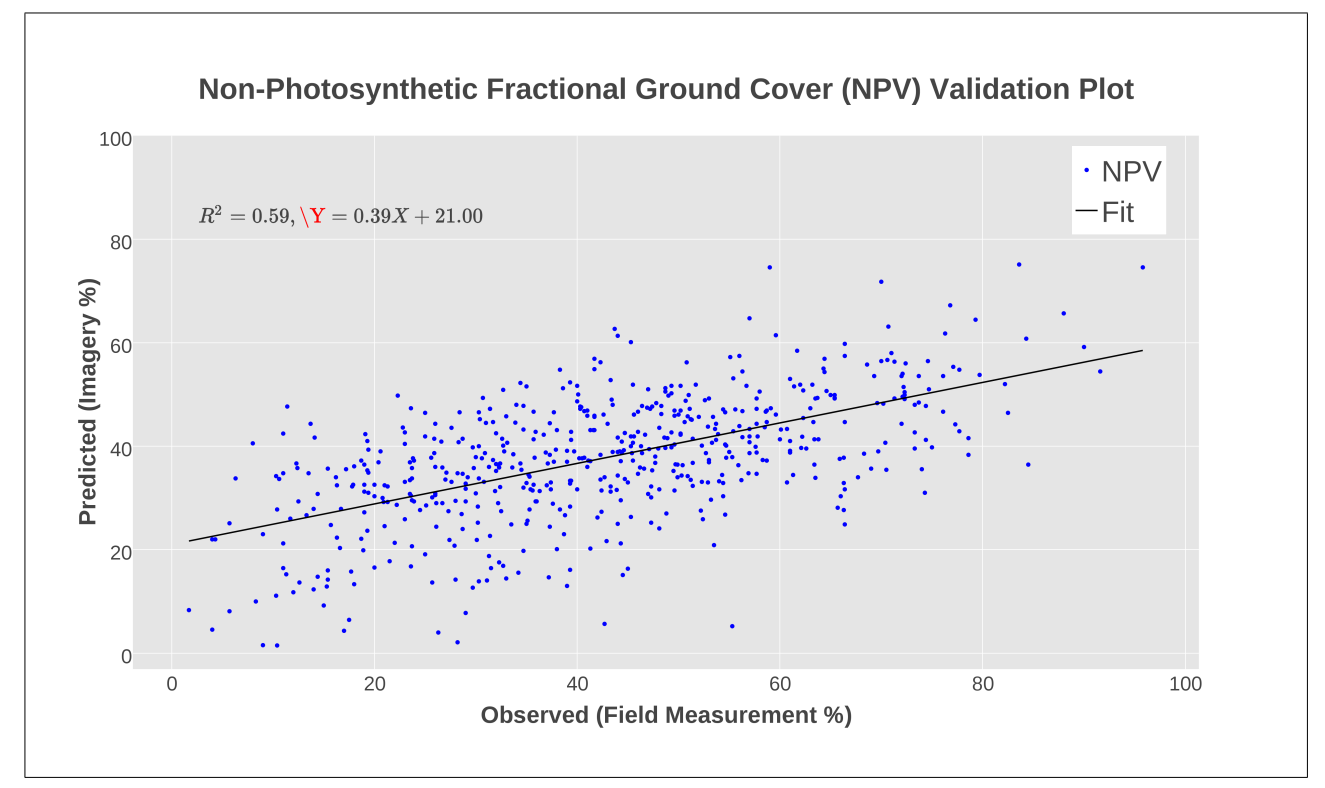

Figure 16. Field site measured NPV compared with coincident date LFGC derived NPV

Figure 16 illustrates the relationship of field measured NPV with the LFGC derived NPV. On the $y$ axis is the coincidentally acquired LFGC NPV fraction and on the $x$ is the measured field NPV fraction.

\section{Discussion}

As [34] and others have stated, 'monitoring vegetation continuously across large landscapes requires robust remote sensing techniques underpinned by accurate field data to calibrate and assess each technique'. Confidence in the underlying LFGC imagery used in this study is first demonstrated. An assessment of both the MODIS and Landsat Fractional Ground Cover products by [34] utilised a subset of the field data used in this study and reported strong relationships between field data and LFGC imagery. Figure 16 illustrates a similar relationship between a further 300+ field sites and LFGC imagery. The LFGC imagery used in this study, in particular the NPV fraction, is an example of a remotely sensed image technique that more accurately depicts ground cover vegetation in arid environments than those used in previous studies [35,36]. Insensitivity to low-photosynthetic material described by [2] has been the primary limitation of past studies and has been demonstrated to have been vastly improved.

Adapting and building upon the time-series analysis methods of [19,37] and others, this method next demonstrates its potential to detect more irregular and less seasonally driven growth cycles across a number of different vegetation types and management regimes in an arid to semi arid climate. Utilising the detected change points in NPV cover, the growth cycles of four example field sites are defined. The effects of climate, landscape characteristics and grazing intensities at each sites time-series are discussed. First site $(\mathrm{A})$ in figure 13 is located in the northern parts of the study area where rainfall is higher and less episodic than the other three sites. Located on an area of productive alluvial soil it has been intensively grazed. Site (A) has the highest dynamic range of NPV growth throughout each growth cycle, expected of a productive, higher rainfall driven and intensively grazed grassland. Site (B) responded to lower and more irregular rainfall. Located on an area of productive calcareous soils, it also has been intensively grazed. In comparison to site (A), this site illustrates longer growth cycles overall and lower overall levels of NPV cover. Site (C) is similar in 
rainfall, soils and grazing intensity to site (B) with the exception that it has been replaced by the introduced perennial Buffel grass (C.ciliaris) species. Able to withstand heavier grazing than site (B), it displays a higher level of cover overall. Site (D) is situated in the extensive spinifex hummock grasslands that encompass large areas of the study area (see map in figure 13). These landscapes are relatively unproductive and only lightly grazed in periods of drought or when more palatable areas have been over-grazed. A persistent pattern of cover is seen, that is typical of an area of minimal grazing. The four examples illustrate differences in landscape, climate and management responses in each time series of NPV cover. A regular and repeatable seasonal component is present to a degree in site (A) whilst the other field sites exhibit more irregular growth cycles. Unlike other methods that aim to decompose the often regular seasonal components of a time series and / or compare from one growth season to another, this study aims to detect individual irregular growth cycles to quantify the components of each cycle as a measure of management practices with their environmental fluctuations minimised.

Management related impacts de-coupled from environmental fluctuations in ground cover is a challenging problem. Previous studies, such as the Dynamic Reference Cover Method (DRCM) of [38] aimed to do so through careful selection of remotely sensed imagery that depicts a period of least climatic influence. Bench mark areas of highest ground cover in the selected dry time are identified and compared with the surrounding landscapes as a measure of management related change. Useful in areas of relatively homogeneous vegetation, the complexities of soil and vegetation across the landscapes of central Australia have proven difficult to make meaningful comparisons within the limitations of available landscape stratification resources. The method in this study takes a different approach in that it attempts to identify the segments of each image pixels time-series with the least climatic influence. Vegetation and management related changes are defined across a much longer and more detailed period than a single dry period point in time. A sample of twenty NPV time-series across each of the four example field sites in figure 14 illustrate such dynamic changes in ground cover. Each shows how time-series of similar characteristics both aggregate and separate from one another throughout their growth cycles. During the initial stages of growth and accumulation in response to rainfall, time series converge and potential differences in vegetation characteristics and importantly management related impacts appear least evident. During the utilisation and decline stages of each NPV cycle, previously described as the period from peak growth to the proceeding growth trough, time series are observed to separate from one another. It is this separation that provides insight to the ability of the method to identify and distinguish differences in grazing related ground cover change. Each of the four field site plots illustrate a gradual separation of each time series in some instances and sudden separation in others, each likely due to differences in management practices and vegetation characteristics. This method differs in that it is able to provide a climate minimised measure of management related change across both time and space with a high degree of detail.

A measure of the degree of management related change is next discussed. Numerous time-series metrics have already been developed. The TIMESAT method of [19] utilises a number of metrics including the area under the curve. This along with a slope based measure of the rate of decline in NPV cover are illustrated in figure 15. The plot of field site (A) shows the slope of each segment's decline to be relatively steep and the area under the curve moderately variable from segment to segment. Site (B) in contrast is more gradual and the area under each curve has a larger proportion of the smaller integral. Site (C) is similar to site (A) and site (D) has the least degree of NPV utilisation. Sites (A,B\& C) are intensively grazed and site (D) less so. Site (B) interestingly is the introduced species of grassland and is more resilient to grazing. Useful insights into management related changes are observed. A better understanding of these changes will lead to more effective monitoring of the changes and trends in rangeland state and condition $[2,4,5]$. 
394

The next stage of the discussion involves the assessment of the detection of change points to distinguish growth cycles in time-series of NPV ground cover. Confidence in the change point detection method is key to the previous distinctions of growth cycles, segmentation of utilisation periods and their associated metrics. As a function of the response of ground cover to rainfall, growth peaks were detected and assessed against peaks in rainfall. Figure 12 shows that less than $6 \%$ of the NPV growth peaks were not associated with peaks in normal to wet conditions. Confidence in the method to detect peaks in individual NPV growth cycles has been demonstrated. Influences of longer term climatic drivers should form the basis of further study.

\section{Conclusions and further research}

A method that utilised and adapted existing techniques was developed and applied in a new approach to the decoupling of management related effects from that of climatic variations. Characterising irregular ground cover growth cycles utilising dense time series methods is a new approach. Seasonally driven growth cycle studies utilising traditional remote sensing image indices are more common. This study demonstrated that an accurate characterisation of episodic rainfall driven growth cycles, that utilised a more appropriate measure of ground cover, is possible. The study further demonstrated the ability to segment each of these growth cycles to isolate periods of minimal climatic influence and provide greater detail of management related ground cover change than previous studies. Opportunities and challenges of further investigations and comparisons of management related change is now a possibility. Part of this research aims to study these changes as further indicators of ground cover resilience and of overall landscape health in an effort to provide land managers and policy makers information on current and historical management of our rangelands.

\section{Acknowledgements}

Support from the Australian Government Research Training Program Scholarship. Support and funding from the University of Queensland Joint Remote Sensing Research Agreement. Support and funding from the NT Department of Environment and Natural Resources / QLD Department of Science, Information Technology and Innovation Collaborative Research Agreement. QLD Department of Science, Information technology and Innovation staff at the Eco-sciences Precinct Remote Sensing Centre for assistance, support, training, advice and access to High Performance Computing Infrastructure including: John Armston, Lisa Collet, Neil Flood, Rebecca Trevithick, Dan Tindall and Fiona Watson. NT Department of Environment and Natural Resources staff and volunteers for assistance in collecting fractional ground cover field data including Gary Bastin, Peter Brockelhurst, Nick Cuff, Jock Duncan, David Hooper, Megan Humphries, Debbie Mitchell, Andrew Scott, Grant Staben, Laurie Tait, Sarah Thorne and Cameron Wallace.

\section{Author contributions}

Prof. Stuart Phinn and Dr. Peter Scarth provided support, advice and supervision as PhD supervisors of the primary author. Robert Denham assisted in the design and implementation of the method and provided example code in its implementation. Jason Barnetson conducted the research and wrote the paper. 
Supplementary Materials: The following Ipython Jupyter notebooks containing all of the python code to carry out the research are available on-line at https://cloud.sagemath.com/projects/ 758e82e5-510d-470e-b0c2-8866faaa654a/files/notebooks/Part1_Select\%20and\%20download\%20image\% 20chip.ipynb https:/ / cloud.sagemath.com/projects/758e82e5-510d-470e-b0c2-8866faaa654a/files/notebooks/Part2_Time\% 20Series\%20image\%20analysis.ipynb

https:/ / cloud.sagemath.com/projects/758e82e5-510d-470e-b0c2-8866faaa654a/files/notebooks/Part3_ Plotting\%20-\%20time\%20series.ipynb

The following LFGC image subsets are also available on-line at: https://www.dropbox.com/sh/ 2u4o2iz0sy1tezz/AAAqo3026AgoJXIZwzGTigvfa?dl=0

Conflicts of Interest: The authors declare no conflict of interest. The founding sponsors had no role in the design of the study; in the collection, analyses, or interpretation of data; in the writing of the manuscript, and in the decision to publish the results.

\section{Bibliography}

1. Westoby, M.; Walker, B.; Noy-Meir, I. Opportunistic Management for Rangelands Not at Equilibrium. Journal of Range Management 1989, 42, 266-274.

2. Friedel, M.H.; Laycock, W.A.; Bastin, G.N. Assessing rangeland condition and trend, 2000.

3. Pickup, G.; Chewings, V.H. A grazing gradient approach to land degradation assessment in arid areas from remotely-sensed data. International journal of remote sensing 1994, 15, 597-617.

4. Pickup, G.; Bastin, G.N.; Chewings, V.H. Identifying trends in land degradation in non-equilibrium rangelands. Journal of Applied Ecology 1998, 35, 365-377.

5. Pickup, G.; Bastin, G.N. Spatial Distribution of Cattle in Arid Rangelands as Detected by Patterns of Change in Vegetation Cover. Source Journal of Applied Ecology Journal of Applied Ecology Journal of Applied Ecology 1997, 34, 657-667.

6. Bastin, G.N.; Ludwig, J. Problems and prospects for mapping vegetation condition in Australia's arid rangelands. Ecological management $\mathcal{E}$ restoration 2006, 7, S71-S74.

7. Ludwig, J.A.; Bastin, G.N.; Chewings, V.H.; Eager, R.W.; Liedloff, A.C. Leakiness: A new index for monitoring the health of arid and semiarid landscapes using remotely sensed vegetation cover and elevation data. Ecological Indicators 2007, 7, 442-454.

8. Bastin, G.N.; Pickup, G.; Chewings, V.H.; Pearce, G. Land Degradation Assessment in Central Australia Using a Grazing Gradient Method. The Rangeland Journal 1993, 15, 190-216.

9. Kennedy, R.E.; Andréfouët, S.; Cohen, W.B.; Gómez, C.; Griffiths, P.; Hais, M.; Healey, S.P.; Helmer, E.H.; Hostert, P.; Lyons, M.B.; Meigs, G.W.; Pflugmacher, D.; Phinn, S.R.; Powell, S.L.; Scarth, P.; Sen, S.; Schroeder, T.a.; Schneider, A.; Sonnenschein, R.; Vogelmann, J.E.; Wulder, M.a.; Zhu, Z. Bringing an ecological view of change to landsat-based remote sensing. Frontiers in Ecology and the Environment 2014, 12, 339-346.

10. Brown, J.; Smith, D. Using soil survey information for site description: a landscape approach. Proceedings of 8th International Soil Management Workshop; USDA Soil Conservation Service, National Soil Survey Centre: Lincoln, Nebraska, 1992; pp. 77-82.

11. Hostert, P.; Griffiths, P.; Van Der Linden, S.; Pflugmacher, D.; Hostert, P.; Van Der Linden, b.S.; Griffiths, P.; Pflugmacher, b.D. Time Series Analyses in a New Era of Optical Satellite Data. In Remote Sensing Time Series - Revealing Land Surface Dynamics; 2015; chapter 2, pp. 25-42.

12. Van Den Bergh, F.; Wessels, K.J.; Miteff, S.; Van Zyl, T.L.; Gazendam, A.D.; Bachoo, A.K. HiTempo: a platform for time-series analysis of remote-sensing satellite data in a high-performance computing environment, 2012.

13. Hostert, P.; Röder, A.; Hill, J. Coupling spectral unmixing and trend analysis for monitoring of long-term vegetation dynamics in Mediterranean rangelands. Remote Sensing of Environment 2003, 87, 183-197.

14. Roberts, D.a.; Dennison, P.E.; Roth, K.L.; Dudley, K.; Hulley, G. Relationships between dominant plant species, fractional cover and Land Surface Temperature in a Mediterranean ecosystem. Remote Sensing of Environment 2015.

15. Scarth, P.F.; Roder, A.; Schmidt, M.; Denham, R. Tracking grazing pressure and climate interaction - the role of Landsat fractional cover in time series analysis. Proceedings of the 15th Australasian Remote Sensing and Photogrammetry Conference, 2010. 
16. Schmidt, M.; Scarth, P. Spectral Mixture Analysis for Ground-Cover Mapping. In Innovations in Remote Sensing and Photogrammetry SE - 27; Jones, S.; Reinke, K., Eds.; Lecture Notes in Geoinformation and Cartography, Springer Berlin Heidelberg, 2009; pp. 349-359.

17. Verbesselt, J.; Hyndman, R.; Newnham, G.; Culvenor, D. Detecting trend and seasonal changes in satellite images time series. Remote Sensing of Environment 2010, pp. 106-115.

18. Jonsson, P.; Eklundh, L. Seasonality extraction by function fitting to time-series of satellite sensor data. IEEE Transactions on Geoscience and Remote Sensing 2002, 40, 1824-1832.

19. Eklundh, L. TIMESAT: A Software Package for Time-Series Processing and Assessment of Vegetation Dynamics. In Remote Sensing Time Series - Revealing Land Surface Dynamics; 2015; chapter 7, pp. 141-158.

20. Tomlinson, K.W.; Poorter, L.; Sterck, F.J.; Borghetti, F.; Ward, D.; de Bie, S.; van Langevelde, F. Leaf adaptations of evergreen and deciduous trees of semi-arid and humid savannas on three continents. Journal of Ecology 2013, 101, 430-440.

21. Roy, D.P.; Kovalskyy, V.; Zhang, H.; Yan, L.; Kommareddy, I.; Roy, D.P.; Kovalskyy, b.V.; Zhang, b.H.; Yan, b.L.; Kommareddy, b.I. The Utility of Landsat Data for Global Long Term Terrestrial Monitoring. In Remote Sensing Time Series - Revealing Land Surface Dynamics; 2015; chapter 14, pp. 289-305.

22. Bastin, G.N.; Pickup, G.; Pearce, G. Utility of AVHRR data for land degradation assessment: a case study. International journal of remote sensing 1995, 16, 651-672.

23. Pickup, G.; Bastin, G.N.; Chewings, V.H. Remote-sensing-based condition assessment for nonequilibrium rangelands under large-scale commercial grazing. Ecological Applications 1994.

24. Flood, N.; Danaher, T.; Gill, T.; Gillingham, S. An Operational Scheme for Deriving Standardised Surface Reflectance from Landsat TM/ETM+ and SPOT HRG Imagery for Eastern Australia. Remote Sensing 2013, 5, 83-109.

25. Flood, N. Continuity of Reflectance Data between Landsat-7 ETM+ and Landsat-8 OLI, for Both Top-of-Atmosphere and Surface Reflectance: A Study in the Australian Landscape. Remote Sensing 2014, 6, 7952-7970.

26. Goodwin, N.R.; Collett, L.J.; Denham, R.J.; Flood, N.; Tindall, D. Cloud and cloud shadow screening across Queensland, Australia: An automated method for Landsat TM/ETM+ time series. Remote Sensing of Environment 2013, 134, 50-65.

27. Muir, J.; Schmidt, M.; Tindall, D.; Trevithick, R.; Scarth, P.; Stewart, J. Field measurement of fractional ground cover: a technical handbook supporting ground cover monitoring for Australia. Technical report, prepared by the Queensland Department of Environment and Resource Management for the Australian Bureau of Agricultural and Resource Economics and Sciences, Canberra, 2011.

28. BOM. Gridded Climate Data, 2015.

29. Jeffrey, S.J.; Carter, J.O.; Moodie, K.B.; Beswick, A.R. Using spatial interpolation to construct a comprehensive archive of Australian climate data. Environmental Modelling E Software 2001, 16, 309-330.

30. Evans, J.; Geerken, R. Discrimination between climate and human-induced dryland degradation. Journal of Arid Environments 2004, 57, 535-554.

31. McKee, T.; Doesken, N.; Kleist, J. The relationship of drought frequency and duration to time scales. Eighth Conf Appl Climatol, 1993.

32. Rabiner, L.; Schafer, R. Digital Processing of Speech Signals. In Signal Processing Series; Prentice Hall: Upper Saddle River, NJ, 1978; p. 147-148.

33. Hänsel, S.; Hänsel, S.; Schucknecht, A.; Matschullat, J. The Modified Rainfall Anomaly Index (mRAI)-is this an alternative to the Standardised Precipitation Index (SPI) in evaluating future extreme precipitation characteristics? Theoretical and applied climatology 2016, 123, 827-844.

34. Guerschman, J.P.; Scarth, P.F.; McVicar, T.R.; Renzullo, L.J.; Malthus, T.J.; Stewart, J.B.; Rickards, J.E.; Trevithick, R. Assessing the effects of site heterogeneity and soil properties when unmixing photosynthetic vegetation, non-photosynthetic vegetation and bare soil fractions from Landsat and MODIS data. Remote Sensing of Environment 2015, 161, 12-26.

35. Hobbs, T.J. The use of NOAA-AVHRR NDVI data to assess herbage production in the arid rangelands of Central Australia. International Journal of Remote Sensing 1995, 16, 1289-1302.

36. Holm, A.M.; Cridland, S.W.; Roderick, M.L. The use of time-integrated NOAA NDVI data and rainfall to assess landscape degradation in the arid shrubland of Western Australia. Remote Sensing of Environment 2003, 85, 145-158. 
540 37. Verbesselt, J.; Hyndman, R.; Newnham, G.; Culvenor, D. Detecting trend and seasonal.

541 38. Bastin, G.N.; Scarth, P.; Chewings, V.; Sparrow, A.; Denham, R.; Schmidt, M.; O’Reagain, P.; Shepherd, $542 \quad$ R.; Abbott, B. Separating grazing and rainfall effects at regional scale using remote sensing imagery: A 543 dynamic reference-cover method. Remote Sensing of Environment 2012, 121, 443-457.

(C) 2017 by the authors. Licensee Preprints, Basel, Switzerland. This article is an open access article distributed under the terms and conditions of the Creative Commons by Attribution (CC-BY) license (http://creativecommons.org/licenses/by/4.0/). 